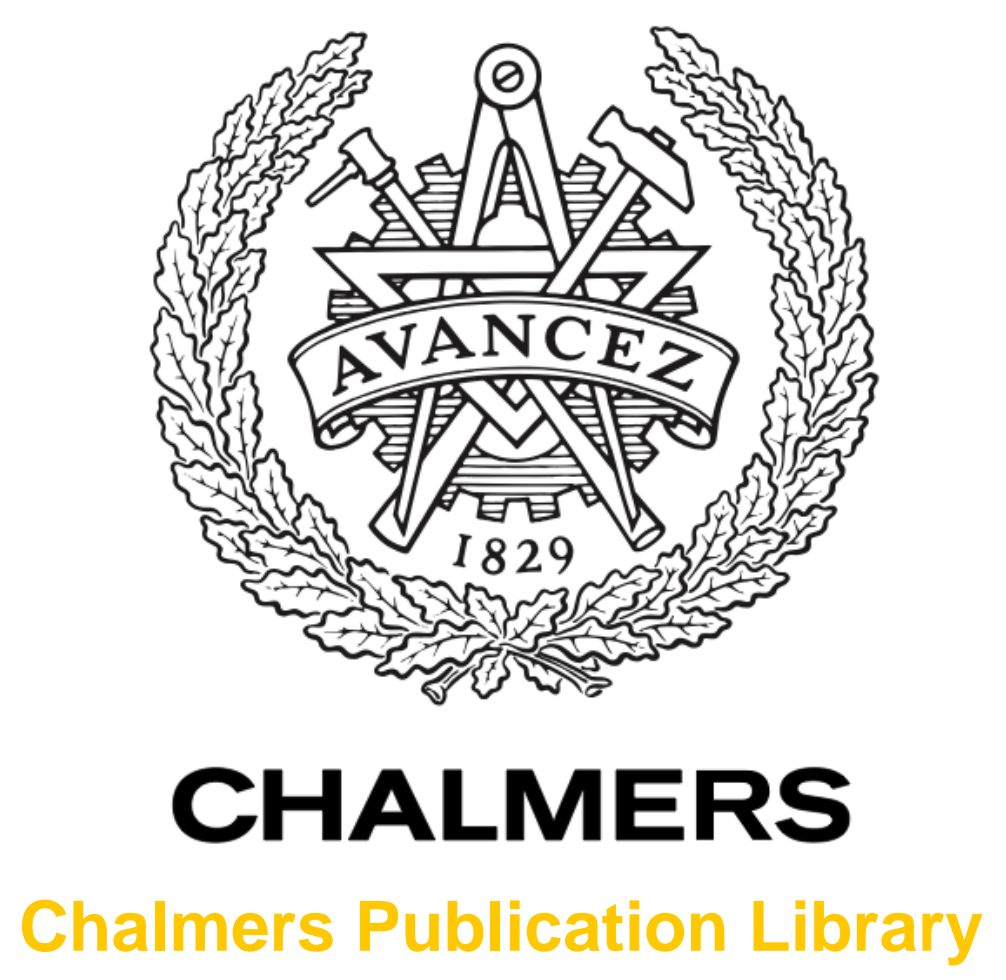

Applying advanced planning systems for supply chain planning: Three case studies

This document has been downloaded from Chalmers Publication Library (CPL). It is the author's version of a work that was accepted for publication in:

International Journal of Physical Distribution and Logistics Management

Citation for the published paper:

Jonsson, P. ; Kjellsdotter, L. ; Rudberg, M. (2007) "Applying advanced planning systems for supply chain planning: Three case studies". International Journal of Physical Distribution and Logistics Management, vol. 37(10), pp. 816-834.

Downloaded from: http://publications.lib.chalmers.se/publication/66897

Notice: Changes introduced as a result of publishing processes such as copy-editing and formatting may not be reflected in this document. For a definitive version of this work, please refer to the published source. Please note that access to the published version might require a subscription.

Chalmers Publication Library (CPL) offers the possibility of retrieving research publications produced at Chalmers University of Technology. It covers all types of publications: articles, dissertations, licentiate theses, masters theses, conference papers, reports etc. Since 2006 it is the official tool for Chalmers official publication statistics. To ensure that Chalmers research results are disseminated as widely as possible, an Open Access Policy has been adopted.

The CPL service is administrated and maintained by Chalmers Library. 
Full reference: Jonsson, P., Kjellsdotter, L., Rudberg, M. 2007. Applying advanced planning systems for supply chain planning: three case studies. International Journal of Physical Distribution and Logistics Management. 37(10): 816-834.

\title{
Applying advanced planning systems for supply chain planning: three case studies
}

\author{
Patrik Jonsson \& Linea Kjellsdotter \\ Department of Technology Management and Economics \\ Chalmers University of Technology, Gothenburg, Sweden \\ E-mail: Patrik.jonsson@chalmers.se \\ Martin Rudberg \\ Department of Management and Engineering \\ Linköping University, Linköping, Sweden \\ E-mail: martin.rudberg@liu.se
}

\section{Abstract}

Purpose: The purpose is to explore how standardized advanced planning systems (APS) can be used for solving planning problems at tactical and strategic levels, and to identify the perceived effects of using APS.

Methodology/Approach: Multiple case studies involving three cases using APS software for strategic network planning and master production scheduling are conducted. Comparative analysis explores how the planning situation, the model design and use of the APS impact the perceived planning effects.

Findings: Findings show how APS support cost-optimised strategic network design in one case and how efficiency, capacity utilisation and delivery service problems were decreased in two cases using APS in global master planning processes. The cases show how APS supports cross-functional integration and supply chain commitment to a common plan. Research directions are suggested about the feasibility of APS in situations with various planning complexities, how design of the optimisation model creates complexity and affects the planning process, data gathering requirements when using APS, the role and design of the planning organisation, and how to achieve positive planning effects, such as finding global optimum and single plan commitment.

Research limitations/implications: The approach is descriptive and explorative. Only three cases are studied.

Practical implications: The findings present experiences of APS usage and identify issues to consider when using APS and potential benefits to gain from usage.

Originality/value: The practical use of APS is low and the knowledge about how it impacts supply chain planning and performance is unexplored. The findings of this article fill some of these gaps.

Keywords: supply chain management, supply chain planning, supply chain design, advanced planning systems, APS, case studies. 
Full reference: Jonsson, P., Kjellsdotter, L., Rudberg, M. 2007. Applying advanced planning systems for supply chain planning: three case studies. International Journal of Physical Distribution and Logistics Management. 37(10): 816-834.

\section{Introduction}

The vision of the supply chain as a holistic construct with close cooperation between the different organisational units has replaced the traditional picture of it as a collection of vertically organised functional units (Stadtler and Kilger, 2005). This, however, leads to a complex planning situation with multiple items, produced at multiple work centres in multi-site production systems. The supply chain complexity is not only a function of the number of links, nodes and items in the network. It is also affected by the level of inter-relationship between the organisational units and variations in organisational culture, size, technology, etc. (Choi and Krause, 2006). Strategic decisions are made over a long planning period, when there is no detailed knowledge of many decision parameters, making the decision environment very uncertain. In the same time the strategic planning is important as it sets the frame for the tactical and operational decisions and many times involves high investments and is costly to change (Zoryk-Schalla et al, 2004). Typical strategic decisions concern the production and distribution capacity, the location of facilities and which products to be manufactured at each plant (Colotla et al, 2003). Melo et al (2005) put forward some problems connected to these kinds of decisions; for example problems of deciding in which periods the capacity of a given set of facilities should be extended to meet increasing demand, problems of deciding were to locate facilities, and problems of optimising the joint logistics when companies are merging. Planning problems of this kind are often quite complex to solve, especially if aiming at optimum solutions, taking capacity constraints and profitability into consideration.

While being aware of the broad area covered by Supply Chain Management (SCM), the research in this article focuses on Advanced Planning Systems (APS), the recent software development that supports planning of the supply chain. Unlike traditional Enterprise Resource Planning Systems (ERP), APS try to find feasible, near optimal plans across the supply chain as a whole, while potential bottlenecks are considered explicitly (Stadtler and Kilger, 2005). In terms of software, APS means a broad group of software applications developed by various software vendors, e.g. i2, Manugistics, Oracle, SAP, AspenTech and Lawson. During the last decade, the use of APS for design, integration, and control of supply chain processes have increased. Especially the interest among industrial companies has increased, some have invested in the software, but only few use them in practice on strategic and tactical planning levels. Almost no research has been conducted about APS usage. There are very few documented cases showing how standardized APS are used, especially descriptions of successes or failures of using APS for supply chain planning on strategic and tactical levels. No broader based empirical study testing and explaining the effects of using APS as support for supply chain planning has been identified. The understanding of when and how to utilise the potential of APS for managing supply chains and what effects could be expected are consequently scarce, both in practice and academia. This gap needs to be closed in order to understand when and how to use APS in supply chain planning.

The purpose of this article is to explore how standardized APS can be used for solving planning problems at tactical and strategic levels, and to identify the perceived effects of using APS. This is done through a comparative analyse among three Swedish firms using APS for 
Full reference: Jonsson, P., Kjellsdotter, L., Rudberg, M. 2007. Applying advanced planning systems for supply chain planning: three case studies. International Journal of Physical Distribution and Logistics Management. 37(10): 816-834.

solving strategic and tactical supply chain problems. In the following sections we describe the methodology and the frame of references. Section four examines the case studies. They are analysed in Section five. Finally, the article is concluded in Section six.

\section{Methodology}

The research is based on a literature review and three case studies. The literature review is founded in the fields of supply chain management, manufacturing planning and control and advanced planning systems. Three cases using standardised APS for solving different types of planning problems at tactical and strategic levels were selected in order to compare and contrast APS usage in the cases. The case studies are descriptive and explorative in nature, and data have been gathered through semi-structured interviews and on-site visits at the case companies, as well as from company internal data and presentations. The authors also had access to primary data in terms of company reports describing processes, performance data, etc. Typically, interviews were carried out with project managers, master planners, and members of the implementation team. To reduce the risk of misinterpretation, at least two researchers participated in the interviews (Kylén, 1994), and case descriptions were communicated back to the interviewees. Interviews were also followed up by telephone and e-mail to verify and clarify data if needed. Furthermore, one author has previous project experiences from two case companies. Another author has done studies with the main respondent of the third case company, increasing the understanding of the companies, its problem and planning processes.

The cases are analysed based on five areas that are proposed to be important when analysing the appropriateness of applying APS in company specific planning environments. The five areas are; planning complexity, planning model and design, planning data, planning organisation and planning effects, which are further described in the last section of the frame of references.

\section{Frame of references}

During the last few years not only APS niche vendors, but also ERP vendors have started developing and implementing advanced planning modules, with the aim to support complex planning problems. APS as a standard decision support system (DSS) for production and distribution planning is however still a new and fairly unexplored tool (Stadtler and Kilger, 2005; Wu et al, 2000)..

\subsection{Supply chain planning using APS}

To be able to plan and control complex supply chain structures powerful management decision support is needed. Planning has, therefore, in the recent years found a renaissance in the use of optimization and simulation tools. APS uses such optimisation and simulation tools. It considers the supply chain constraints and produces near optimal plans and is therefore sometimes called supply chain optimization software. Cost minimization and profit maximization are the two most common ways to control the solution (Stadtler and Kilger, 2005). APS can be defined and explained through different perspectives but commonly APS is viewed as an extension of ERP. On the other hand, standard APS modules stem from the many 
Full reference: Jonsson, P., Kjellsdotter, L., Rudberg, M. 2007. Applying advanced planning systems for supply chain planning: three case studies. International Journal of Physical Distribution and Logistics Management. 37(10): 816-834.

in-house developed decision support systems (DSS) that aid planners at various levels in the decision hierarchy (De Kok and Graves, 2003). The literature reports on some successful implementations of DSS in either special supply chain planning situations or optimization models regarding the entire chain. Gupta et al (2002), for example, describe a DSS that helps Pfizer to plan their distribution network. The model is useful in both strategic and operational planning situations. Brown et al (2001) presents a large-scale linear programming optimization model used at Kellogg Company to support production and distribution decision making on both operational and tactical levels. Arntzen et al (1995) comprehensively describe supply chain optimization at Digital Equipment Corporation.

Nowadays, APS-modules are often a part of larger software suites and work as add-ons to existing ERP-systems. APS does not replace ERP, it extracts data from the ERP database and sends the resulting plans back for distribution and execution. Often, solver engines based on linear programming and mixed integer programming is used to unravel the large amount of data. To cut computing time, heuristics are used built on operations research knowledge (De Kok and Graves, 2003). APS, consequently, tries to automate and computerize the planning through simulation and optimization. Still the decision-making is done by planners who have insight in the particular supply chain, know about the system constraints and also have a feeling about feasibility in the plans that are created. Planners also do the modelling and decisions regarding use of input to the model. APS is, thus, based on a systems and process approach and tries to bridge the gap between the supply chain complexity and the day-to-day operative decisions. Three main characters of APS are; integral planning, true optimization and hierarchical planning system (Fleishmann and Meyr, 2003). Stadtler and Kilger (2005) define the goal with APS as "...to find feasible, near-optimal plans across the supply chain as whole, while potential bottlenecks are considered explicitly”.

\subsection{Structure and functionality of APS}

Considering the complex environment that most companies have to cope with, most decisionsupport systems advocates a hierarchical distribution of the decision-making processes, where the next upper level coordinates each lower level (Wortmann et al., 1997). Strategic decisions (long horizon and long periods) cannot be based on the same level of detail in the information as is the case for operational decisions (short horizon and short periods). Hence, decisions made at a high hierarchical level are normally based on aggregated information (in terms of product families, factories, etc.) and aggregated time periods. Thereafter these high level decisions form the context for the decision-making processes at lower-level decision centres, where decisions are disaggregated into more detailed information and time periods, but the considered horizon is made shorter. Decisions are thus exploded through the hierarchical structure until the lowest level is reached and detailed decisions are executed (cf. Figure 1).

One way to classify standard APS is by categorizing different modules depending on the length of the planning horizon on the one hand, and the supply chain process that the module supports on the other. Figure 1 categorizes the most common standard APS modules according to these two dimensions (Stadtler, 2005; Meyr et al, 2005). This module segmentation is commonly used among software vendors. This study focuses on the strategic and tactical levels, i.e. strategic network design and multi-site master planning in Figure 1.

Strategic network design (SND) is intended to provide support for key strategic decisions concerning the configuration of the supply chain on a three to ten years planning horizon 
Full reference: Jonsson, P., Kjellsdotter, L., Rudberg, M. 2007. Applying advanced planning systems for supply chain planning: three case studies. International Journal of Physical Distribution and Logistics Management. 37(10): 816-834.

(Entrup, 2005). The SND module must tie together all relevant decision variables and constraints over a long planning horizon leading to that product, capacity and customer data must be aggregated to get a solvable model size. Due to model complexity and solvability, stochastic features are typically not included in standard APS, although future estimates incorporate a high degree of uncertainty (Entrup, 2005). Instead, companies typically develop a set of scenarios to establish upper and lower bounds and a typical (most realistic) case. The models are defined as LP or MILP models depending on the planning issues to address and to achieve reasonable solution times a great deal of technical expertise is required to limit the model size (Goetschlalckx et al., 2002). Hence, the primary users are business development departments or consultancies. Companies using a SND model normally run it either as a onetime analysis as a part of a supply chain redesign project, or on an annual basis during the yearly budgeting process. Although the results of the SND module have the highest impact on the supply chain (Entrup, 2005) there are still only few companies using it on a regular basis.

Figure 1: Typical APS planning structure and categorization of APS modules.

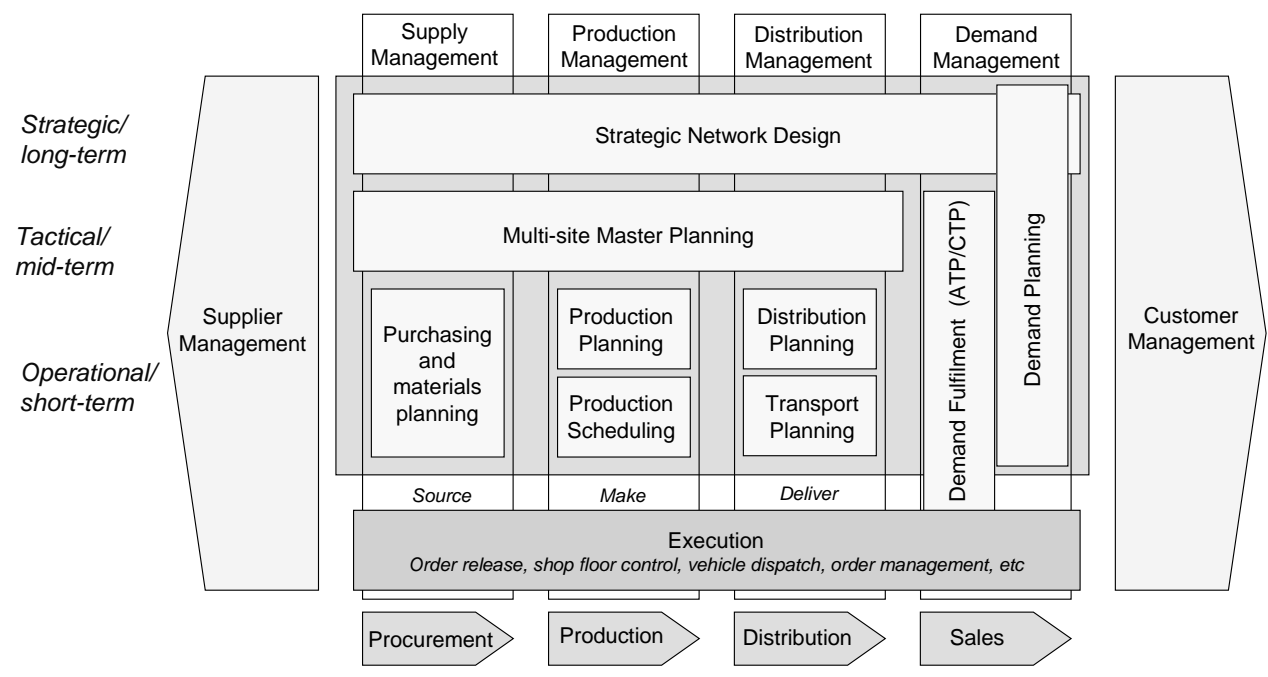

Multi-site master planning (MMP) aims at synchronizing the flow of materials along the supply chain, and thereby balancing demand and capacity. It supports the mid-term decisions concerning efficient utilisation of production, distribution and supply capacities (Stadtler and Kilger, 2005). MMP not only balances demand with available capacities but also assigns demands (production and distribution amounts) to sites in order to avoid bottlenecks, wherefore it has to cover one full seasonal cycle, or at least 12 months in terms of weekly or monthly time buckets. Due to the complexity and detail required in the model only constrained (or near-constrained) resources are modelled in detail. To increase the solvability of the model, most vendors distinguish between hard and soft constraints in the LP or MILP model that is used (Entrup, 2005). While hard constraints have to be fulfilled, the violation of soft constraints only renders a penalty in the objective function. As for the SND module, also the MMP model uses aggregation to establish reasonable solution times. The solvers included in the standard APS modules are often a combination between internally developed and third 
Full reference: Jonsson, P., Kjellsdotter, L., Rudberg, M. 2007. Applying advanced planning systems for supply chain planning: three case studies. International Journal of Physical Distribution and Logistics Management. 37(10): 816-834.

party solvers. Companies using the MMP module often have an established sales and operations planning process or a centralised master planning function. One important feature of the MMP module is the ability for companies to coordinate sourcing, production, distribution and seasonal stock decisions on a multi-site basis. Besides the positive planning effects the MMP is also intended to enhance visibility and coordination throughout the supply chain. Yet, the MMP module is seldom found at companies today, although it has gained more interest in recent years.

\subsection{Using APS}

Studies show that there are several problems involved in efficiently and effectively using planning software. Several of these problems are related to the planning complexity, software complexity, lack of training and knowledge among managers and personnel, low data accuracy, and lack of support from the software vendor (e.g. Petroni, 2002). Most of these studies focus on ERP systems, especially MRP environments. Studies on ERP implementation also conclude that top management's support together with personnel education and training about the software and planning processes are of vital importance for successfully implementing an ERP system, but also for running the system after implementation (Petroni, 2002; Muscatello et al., 2003). The findings should be possible to relate to APS applications as well (Stadtler and Kilger, 2005). The problems could be expected to be even more severe for APS, for example, because several functions and organizations may be involved in the planning process and because the requirement of real time data may be higher than in ERP. We propose that the appropriateness of using APS could be related to the following areas:

Planning complexity: Dealing with high planning problem complexity is a main feature of APS (De Kok and Graves, 2003; Chopra and Meindl, 2004). We could distinguish between complexity in the physical supply chain structure (e.g. the number of links, nodes, capacity processes, item groups) and complexity in decision making (e.g. including several trade-offs between different business constraints and decision rules such as customer and item priorities). $\mathrm{t}$ is reasonable to believe that the appropriateness of using APS increases when the planning complexity increases. But there may also be situations that are too complex or containing "wrong type" of complexity for APS to solve.

Planning model and design: The APS effects should also be affected by the planning model design, i.e. how the appropriate optimization functions, aggregation levels and number of constraints for a specific planning problem is chosen. Various types and degrees of complexity may also affect the appropriateness of using cost and profit optimization. It is also reasonable to believe that standardised APS may have some drawbacks compared to custom-made APS, because the optimisation problem differs between companies and it is hard to create an APS that fits many companies well.

Planning data: All planning is based on a vast amount of data. This is also the case for supply chain planning using APS. The need for accurate data is especially high when working with finite capacity and real-time planning (APICS, 2007). Data collection and validation, consequently, have to be conducted in appropriate ways. The amount and accuracy of data and ease of designing and analysing supply chain planning models on strategic and tactical levels also depend on the level of data aggregation. Higher aggregation levels results in fewer planning objects and could reduce the uncertainty in the planning data, but on the expense of lower details. The same effects can be achieved by using larger time buckets. Furthermore, 
Full reference: Jonsson, P., Kjellsdotter, L., Rudberg, M. 2007. Applying advanced planning systems for supply chain planning: three case studies. International Journal of Physical Distribution and Logistics Management. 37(10): 816-834.

strong coordination between the different planning modules is a must in order to achieve consistent plans for the different planning levels and different entities in the supply chain (Stadtler and Kilger, 2005). Besides, APS need to be integrated in an existing IT infrastructure, for example APS needs to be integrated with ERP and Data Warehouses storing the basic data. Planning data problems concern in what planning situations the gathering and registering, and resulting quality, of basic planning data is critical for the APS planning performance. There are obvious links between planning complexity and the criticality of data gathering and registration.

Planning organisation: Solving complex supply chain planning problems using APS is not only an issue of designing a proper optimisation model and securing accurate basic data. The design and functioning of the planning organisation may also have important impact on the planning performance, especially when different functional and organisation units affect and are affected by the planning. It is not obvious what characterizes appropriate planning organization design in different planning situations, for example, when conducting event-based planning, involving geographically distant sites, requiring global visibility of critical paths and what if analysis. Neither, is it clear what education and training is necessary in order to utilize the potential of APS for planning on strategic and tactical levels.

APS, consequently, deals with complex planning problems, using an optimisation-based planning model and design, relying on a vast amount of planning data and is carried out by a planning organisation. The case study analysis focuses on these issues and the perceived effects of using APS.

\section{Case studies}

The three cases use standard APS-modules for solving planning problems on a strategic or tactical level. All companies are continuous process type companies and use "supply chain planners” from different vendors, although they face different planning problems.

\subsection{Case I - AArhusKarlshamn}

\subsubsection{Company characteristics and planning problem}

The company AArhusKarlshamn (AAK) is a recently established company making vegetable oils and fats. It emerged through a merge between the Danish company Aarhus United A/S and the Swedish company Karlshamns AB. Marketwise, the two companies complement each other well; Karlshamns with large markets in Scandinavia and Central and Eastern Europe and Aarhus United with strong market positions in Western Europe, the US and Latin America. The presence in North America offers great opportunities for expanding the companies within speciality fats. Both companies also have ambitions within the fast food market, which can be based on a very strong foundation in United Kingdom. In terms of purchasing, the merger may also lead to efficiency gains. Both companies source many of their raw materials in South East Asia and Africa. Cooperation and a strong foothold in the markets could possibly strengthen the company's competitive ability.

Another outcome of the merger is that it has left the new company with two identical production sites in the same geographical area, northern Europe. It is not obvious how to 
Full reference: Jonsson, P., Kjellsdotter, L., Rudberg, M. 2007. Applying advanced planning systems for supply chain planning: three case studies. International Journal of Physical Distribution and Logistics Management. 37(10): 816-834.

utilize the two facilities in the most optimal way, i.e. what assortment to make at the respective site or what markets to serve from the respective site.

\subsubsection{Planning processes and planning modules}

In order to utilize the two production facilities and achieve low total logistics costs in the entire supply chain, a supply chain network design analysis using Lawson M3 Supply Chain Planner was conducted. The objective of the analysis was to compare the total logistics costs of the following five alternative supply chain set-up scenarios:

1. Baseline: This illustrates the situation before the merge. The Swedish plant can produce everything and supplies the "Swedish" demand in all markets. The Danish plant can produce everything and supplies the "Danish" demand in all markets. No goods flow between plants.

2. Focused factory: In this scenario the respective production site focuses on unique products. No product is made at both plants. Some production processes are consequently closed in the respective plant. Still, both plants have processes for component and final production. All components used in the final production of a product are not produced at the same production site as the final production. Transportation of components between the sites is allowed.

3. Focused market: In this scenario the different production sites make all products (i.e. as was done before the merge) but they supply unique markets. The Danish plant supplies the Western Europe and overseas markets while the Swedish plant supplies Eastern Europe and Scandinavia. No goods flow between the plants.

4. Segmented supply chain: In this scenario the Danish plant is converted into a component producer, supplying the Swedish plant with components for final production. The Danish plant closes processes related to the final production steps, e.g. bulk loading, can filling, fat container filling, box filling and lego production. The Swedish plant closes down some component manufacturing processes and focuses on some other component manufacturing processes and all final production processes. In this scenario the Danish plant is consequently transferred into a component producer. All components can be transported from Denmark to Sweden but there is no transportation the other way around.

5. Focused factory excluding one product group: This scenario is similar to scenario two, except for final production of one product group that is conducted at both sites. All components can be transported between the production sites.

The planning model used to test the scenarios consisted of three types of nodes; markets, production sites and suppliers. 49 different market nodes were defined, one for each country. More than 49 different markets existed in reality but small markets were excluded. There were two production sites, one in Sweden and one in Denmark. The production process at each site consisted of processes related to component production and final production. All together, fifteen different production processes were defined and used in the model. Four global main suppliers supplied both production facilities with raw materials.

Only bulk transportation using ship was possible from suppliers to production sites. Truck transportation was used for material flows between the plants. Two transportation alternatives were available between production sites and markets: bulk using ship or in pieces using truck. Production capacities were set to equal the present capacity levels at the two plants. Infinite capacities were used for the supply and transportation processes. 
Full reference: Jonsson, P., Kjellsdotter, L., Rudberg, M. 2007. Applying advanced planning systems for supply chain planning: three case studies. International Journal of Physical Distribution and Logistics Management. 37(10): 816-834.

Five cost types were included in the model: production, outbound transportation, inbound transportation, inventory and purchase costs. Estimates for transportation, production and purchasing costs were based on actual figures for the Swedish plant. Production and purchasing costs were set equal for the Swedish and Danish plants. Inventory costs were calculated using the present inventory carrying cost percentage of the Swedish company. Six types of raw material were bought from the suppliers. About 1200 end products were aggregated to about 700 product groups with similar raw material and capacity need. The demand for the 49 markets was based on the actual sales of 2005. No sales price was included in the model. Two six months time buckets were used.

Linear and mixed-integer programming using Lawson M3 SCP was conducted. The objective function was infinite optimization finding minimum total cost. Finite optimization was not used in order to not exclude any possible solution and because one aim of the analysis was to find the low cost situation, where over-utilisation in the present capacities are accepted, and new production investment needs are identified.

\subsubsection{Execution and effects}

Scenario three, focused market, resulted in the lowest total costs and scenario two the highest costs. The main reason for the higher costs in scenario two is that some of the products moved from Sweden to Denmark are more costly to distribute from Denmark. In scenario three, where all products can be shipped from both production sites, the total logistics costs are minimized. In scenarios four and five, the total logistics costs were slightly higher than the base line. The conduced cost optimization did not consider the fixed and administrative cost effects of closing production processes in Denmark, and costs for IT, organization, etc. The cost effects of closing processes are small in all scenarios except for scenario four where all processes related to final production are closed. These potential cost savings in scenario four are considered to exceed the higher logistics costs compared to lowest cost scenario three in the optimization model. If considering the total annual cost savings of closing these processes, scenario four is, consequently, the optimum scenario with the lowest total costs.

The supply chain design analysis at AAK was only conducted at one time. The aim was to use the results as input to the supply chain design decisions after the merger. However, the ambition when setting up the model was to be able to use it also on a continuous basis for master planning on a tactical level. This has not been the case.

One person worked full time for about a month to gather and register data for the model. Most data was exported from the ERP system, manually adjusted, imported and typed into Lawson M3 SCP. A materials planner, a distribution planner, two software consultants and the supply chain manager at Karlshamns $\mathrm{AB}$ together spent a total of two months of full-time work on designing and running the model. The total time for data gathering and designing and running the model was consequently about three full-time working months.

No formal planning organization was set-up for the analysis but the results were used as input to the supply chain design discussion between the two previous firms. The fact that one of the original organizations was responsible for developing the model decreased the commitment to and use of its results. The other organization did not feel commitment to the results in the same way as the one that developed the model. 
Full reference: Jonsson, P., Kjellsdotter, L., Rudberg, M. 2007. Applying advanced planning systems for supply chain planning: three case studies. International Journal of Physical Distribution and Logistics Management. 37(10): 816-834.

\subsection{Case II - Svenska Lantmännen}

\subsubsection{Company characteristics and planning problem}

Svenska Lantmännen (The Swedish Farmers Supply and Crop Marketing Association) is one of the leading groups within the grocery and agriculture industry in Sweden. It is a producer cooperative that works together in marketing, distribution, sales, processing and supply. Large profit margins are not the goal so much as cost reduction through the entire chain. This is due to that the owners, some 50,000 Swedish farmers, are both suppliers and customers to the central production and distribution function. The core business has some 1,500 employees in 13 geographically separate areas in Sweden and supplies its customers with seed, fertilizers and feed among other things, and of course process and sells what the farmers produce. Prior to 2001 the farmers acted in local and regional cooperatives but in 2001, Svenska Lantmännen was founded out of merging these cooperatives. Since then the group has suffered from inefficiency and surplus capacity. Several structural changes and reorganisations have been carried out in order to streamline the business. In 2004, a major restructuring of the seed supply chain was undertaken. Two out of six production plants was shut down and two out of four central warehouses were closed. Restructuring the seed supply chain resulted in less capacity in both production and warehouses.

Today, every plant supplies a restricted number of customers within the nearest geographical regions. Only in a few cases the production is differentiated between the plants. The main distribution strategy is to ship finished products directly from the finished products inventory at the plants. This leads to a large number of distribution relations that put pressure on transportation efficiency. The seed product group contains about 270 different SKUs that show a typical 80/20-volume ratio. The final products are sold in discrete entities in form of 20 to 700 kilogram bags and the raw material is supplied as bulk. The demand for seed is highly seasonal, and about $70 \%$ of the volume is sold during a period between December and March. The large volumes and the many suppliers and customers make the business dependent on efficient inventory and distribution management. The planning process is difficult due to the high seasonal fluctuations and the fact that seasonal stock can only be built up in restricted amount.

\subsubsection{Planning processes and planning modules}

The restructuring of the supply chain was complemented by changes in the mid-term supply chain master planning in form of a new centralized planning function. Earlier the mid-term planning (including production and distribution) had been carried out locally/regionally. In addition the new centralized planning function was in need of computing decision support in order to find feasible plans for the entire supply chain. The logistics division investigated the use of decision support through APS in a feasibility study in mid 2004. Two months later the mid-term supply chain master planning APS module Lawson M3 Supply Chain Planner (M3 SCP) was implemented and in use.

The tactical planning process and related APS modules are visualized in Figure 2. Sales forecasts are conducted by the marketing and sales function and are mainly dependent on historical sales data. To be able to meet the high seasonal demand peaks surplus capacity is needed in the supply chain. Furthermore, the access to raw material is in great extent dependent on weather and other factors that are hard to predict. 
Full reference: Jonsson, P., Kjellsdotter, L., Rudberg, M. 2007. Applying advanced planning systems for supply chain planning: three case studies. International Journal of Physical Distribution and Logistics Management. 37(10): 816-834.

Figure 2: Svenska Lantmännen’s tactical planning process and related APS modules.

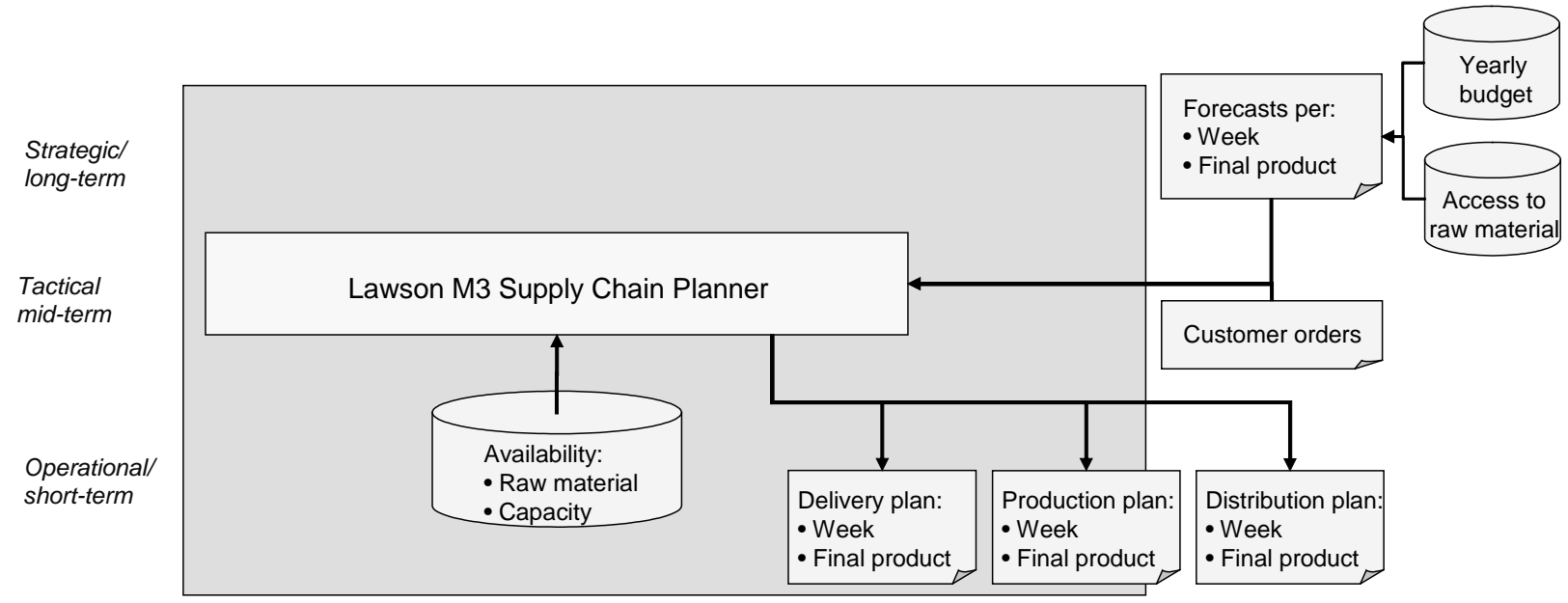

Planning with M3 SCP balances supply and demand for each weekly time bucket during the planning horizon (the remaining season). Forecasts are based on the yearly budgeting process and only updated twice a year. Production and inventory levels are matched with capacity for each period to minimize total supply chain costs. The planning process with M3 SCP is done in an iterative manner where bottlenecks are identified and handled by the planner. Data is extracted from the company's ERP system and used by the M3 SCP module. The solver engine uses linear and mixed-integer programming to solve the planning problem with respect to total cost minimization. Short-term production scheduling as well as planning supply is carried out locally at the plants according to the directions given by the aggregated master plan. Transport planning (routing, loading, etc.) is outsourced to a third party that executes the deliveries within the frames of the distribution plan.

\subsubsection{Execution and effects}

In a study carried out in 2005 (Andersson, 2005), the effects on total costs regarding the seed production and distribution at Svenska Lantmännen was evaluated. At the same time, the flow of goods and the implementation of the APS at the centralized master planning function were investigated. The results show that the structural changes and the implementation of the APS have streamlined the production and distribution network regarding the flow of goods. Total costs have decreased by some $13 \%$ on a yearly basis, while at the same time the quantity of sold units has increased. This results in a total reduction of cost by some $15 \%$ per tonne. Furthermore, inventory levels in production facilities and warehouses were reduced by almost $50 \%$, and inventory reductions were realized for raw material, WIP and finished products.

The supply chain planning trade-off have had the following consequences: in general increased production batch sizes, slightly higher transportation costs due to lower fill-rates, decreased production cost and less capital tied up in inventory because of better throughput. The reinvented supply chain planning has reduced the total planning time. Central planning has increased the control of material flows in the chain as well as the cost structure. A higher 
Full reference: Jonsson, P., Kjellsdotter, L., Rudberg, M. 2007. Applying advanced planning systems for supply chain planning: three case studies. International Journal of Physical Distribution and Logistics Management. 37(10): 816-834.

understanding of the supply chain trade-off makes further development of immediate importance. Optimizing the supply chain has not been the most important objective with the APS implementation. The main focus has been to gain acceptance for the central master planning function and enable communications between functions. Acceptance for this APS in the rest of the organization made it possible to consider further APS implementations. More structural changes through rationalisation and more products will in the future go under central APS planning. In addition to the monetary gains by the restructuring, the new way of planning increased the communication between logistics, manufacturing, marketing and sales functions.

\subsection{Case III - SSAB Oxelösund}

\subsubsection{Company characteristics and planning problem}

SSAB Oxelösund is a member of the SSAB Svenskt Stål AB Group and is the biggest Nordic manufacturer of heavy steel plates. The company is also a world leader in the specialist field of quenched and tempered steels, with brand names such as HARDOX and WELDOX. SSAB Oxelösund, with an integrated process extending from iron raw material to finished plate, produces around 632,000 tonnes of heavy plate (2005) of which $90 \%$ are exported. Germany is the biggest single export market, but SSAB Oxelösund carries finished goods inventory in more than 40 countries around the world. At the end of the fiscal year 2005 SSAB Oxelösund had sales of SEK 9.2 billion and a yearly profit of 2 billion, with close to 2,500 employees.

Traditionally SSAB Oxelösund's tactical master planning process was made up of a series of disintegrated and manual procedures aided by various spreadsheets and small local databases. Considering the large number of regional sales managers (close to 100 at the time), the large numbers of SKUs, the company's global spread and the fact that the company strives for the high-end, high-profit market (which includes customers with high demands), the planning situation became untenable. Customer service, and especially on-time-deliveries, is considered to be the order winner, but the manual planning procedures resulted in poor performance on this important criterion. Furthermore, the demand for SSAB Oxelösund's products is higher than what the present production facility can produce. In that sense, it also becomes important to prioritize among customer orders in order to satisfy the most important customers and to maximize profits. Within the existing planning processes, some resources were over-utilized and others under-utilized. The acceptance of the sales forecasts in production was low and the trust among the market and sales force in the production capacity was low, i.e. there was often a misunderstanding between production, marketing and sales.

\subsubsection{Planning processes and planning modules}

In 2001 SSAB Oxelösund initiated a project to streamline its tactical planning and to find suitable decision support systems to achieve an effective master planning for the entire company. After a thorough selection process SSAB Oxelösund choose to implement a product suite from i2 Technologies to address the planning problems. In 2002 i2's Demand Planner (i2 DP), Supply Chain Planner (i2 SCP) and Demand Fulfillment (i2 DF) was up and running. The tactical planning process and the related APS modules are visualized in Figure 3. 
Full reference: Jonsson, P., Kjellsdotter, L., Rudberg, M. 2007. Applying advanced planning systems for supply chain planning: three case studies. International Journal of Physical Distribution and Logistics Management. 37(10): 816-834.

Figure 3: SSAB Oxelösund's master planning process and related APS modules.

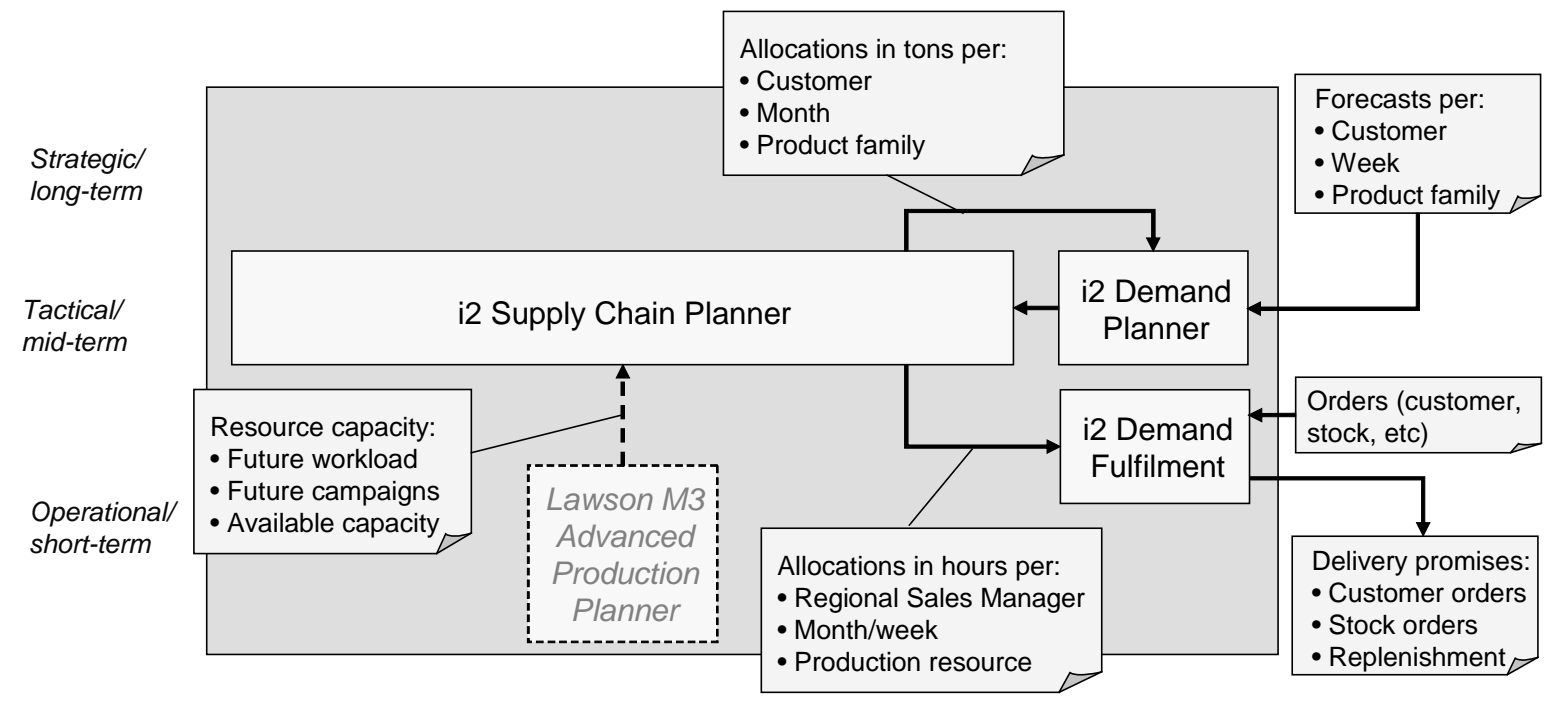

The tactical master planning process starts with forecasts produced by some 100 regional sales managers that are entered into i2 DP. The forecasts are thereafter consolidated and transported into the i2 SCP. The forecasts used to feed the i2 DP and i2 SCP are based on three dimensions; geography, product, and time. The geography dimension describes SSAB Oxelösund's sales organisation and it goes all way down to consignee. SSAB Oxelösund's market consists of some 1000 major customers that are divided into approximately 100 sales regions, each managed by a regional sales manager. The regional sales managers are responsible for providing forecasts on a rolling 18 months time horizon, of which the first 6 months should have "high" forecast accuracy. Each forecast includes data on sales volume per customer (in tonnes) and also sales price for each product group in monthly time buckets. In total SSAB Oxelösund has around 250 different product groups and the sales manager typically carries 20 customers in his account. Hence, there are a lot of forecasts that have to be consolidated in the demand planner before the data is exported to i2 SCP.

The aggregated forecast from i2 DP is imported into the i2 SCP where the forecasts are matched to the available capacity based on a set of priorities and business rules. The forecasts are disaggregated from monthly to weekly buckets for the first 12 weeks and the basic capacity data used in the SCP optimisation is imported from the Lawson M3 APP system. The demands put upon SSAB Oxelösund are much larger than the available capacity, wherefore the aim of the SCP optimisation is to match the forecasted demand with the available capacity based on profit maximization and a pre-defined set of business rules. The results of this process are then exported back to the i2 DP in tonnes to direct the sales manager in terms of resource allocation, and to the i2 DF in terms of available capacity in hours per priority group to quote delivery promises on a short-term basis.

i2 DF is the unit that keeps track of the allocated hours per sales region and makes the customer order promises, based on an available/capable-to-promise calculation. When an order 
Full reference: Jonsson, P., Kjellsdotter, L., Rudberg, M. 2007. Applying advanced planning systems for supply chain planning: three case studies. International Journal of Physical Distribution and Logistics Management. 37(10): 816-834.

is entered into SSAB Oxelösund's Order Entry System the requested delivery time and volume is checked in i2 DF and if capacity is available within the inquired lead time, a delivery promise is returned. In order to handle the fluctuations in sales that always occur, SSAB Oxelösund has the possibility to use business rules built into the system. These rules are set up individually for each business area. When the system cannot find capacity within own allocation the system starts looking elsewhere until capacity can be found.

\subsubsection{Execution and effects}

The key goals of implementing the i2 suite were to handle the excess demand (scarce capacity) and to improve delivery performance. The capacity problem is temporarily solved through the use of finite master scheduling aiming at maximizing profits by using available capacities, after prioritized orders are scheduled, for the most profitable orders. As such less profitable orders are rejected to cope with the limited capacity. In the long term SSAB Oxelösund is shopping for more capacity, both internally and externally. Looking at the delivery reliability since the APS modules were implemented, it is not obvious that the goal is fulfilled. The delivery performance has, on average, been kept at a fairly stable and slowly increasing level. However, since the time of the implementation demand has increased heavily and SSAB Oxelösund has suffered from two severe breakdowns. Normalising data from these effects (increased order stock and breakdowns) it is clear that the APS suite has had positive effects on delivery performance. Besides, the communication and confidence between marketing and production has increased through the increased visibility of demand and delivery promises. Another consequence of the APS implementation is that the process and demand uncertainties have decreased and as a result of that, the inventory levels have been reduced (however also affected by the increased demand).

\section{Analysis and conclusion}

Here, the three cases are compared in order to explore why and how APS was used and what it resulted in. Table I contains a summary of the case characteristics. All three cases used SCP optimization software for planning on strategic and tactical levels. However, AArhusKarlshamns (AAK) used it to generate decision support for cost efficient supply chain design. This planning was only conducted at one single time, when merging two companies. Svenska Lantmännen (SL) and SSAB Oxelösund (SSAB) used it for continuous master production scheduling in situations with finite capacity constraints. The planning problems are, consequently, quite similar for SL and SSAB but different for AAK. In all three cases, the overall aim of using APS was to create holistic perspectives of complex planning problems, eliminate sub-optimization and achieve commitment to an “optimum” plan. 
Full reference: Jonsson, P., Kjellsdotter, L., Rudberg, M. 2007. Applying advanced planning systems for supply chain planning: three case studies. International Journal of Physical Distribution and Logistics Management. 37(10): 816-834.

Table I. Summary of case characteristics

\begin{tabular}{|c|c|c|c|}
\hline Issue & AArhusKarlshamn (AAK) & Svenska Lantmännen (SL) & SSAB Oxelösund (SSAB) \\
\hline $\begin{array}{l}\text { Demogra- } \\
\text { phics }\end{array}$ & $\begin{array}{l}\text { Manufacturing oils and fats. } \\
\text { Merger, between a Swedish and } \\
\text { a Danish plant. Global customers } \\
\text { and suppliers. }\end{array}$ & $\begin{array}{l}\text { Producer cooperative. Swedish } \\
\text { farmers are supplier/customer } \\
\text { and own the cooperation. }\end{array}$ & $\begin{array}{l}\text { Biggest Nordic manufacturer of } \\
\text { heavy steel plates. Integrated } \\
\text { processes. Customer worldwide, } \\
\text { subsidiary in } 40 \text { countries. }\end{array}$ \\
\hline $\begin{array}{l}\text { Physical } \\
\text { Supply chain } \\
\text { structure }\end{array}$ & $\begin{array}{l}\text { Few suppliers, two production } \\
\text { facilities with multiple capacity } \\
\text { units and finished products in } \\
\text { several markets. }\end{array}$ & $\begin{array}{l}\text { Some } 50,000 \text { farmers that are } \\
\text { both suppliers and customers to } \\
\text { five production sites and } 4 \\
\text { distribution centres. }\end{array}$ & $\begin{array}{l}\text { Infinite supply, one production } \\
\text { facility with multiple capacity } \\
\text { units and finished products in } \\
\text { multiple markets. }\end{array}$ \\
\hline $\begin{array}{l}\text { Planning } \\
\text { level }\end{array}$ & Strategic supply chain design. & $\begin{array}{l}\text { Constraint-based master } \\
\text { production scheduling with a } \\
\text { focus on distribution and } \\
\text { transportation. }\end{array}$ & $\begin{array}{l}\text { Constraint-based master } \\
\text { production scheduling and } \\
\text { capable-to-promise calculation. }\end{array}$ \\
\hline $\begin{array}{l}\text { Planning } \\
\text { problem }\end{array}$ & $\begin{array}{l}\text { How to utilize two identical } \\
\text { production sites in the most cost } \\
\text { efficient way. }\end{array}$ & Inefficiency and overcapacity. & $\begin{array}{ll}\text { Capacity } & \text { shortage and } \\
\text { utilisation. } & \text { On-time-deliveries } \\
\text { not reached. } & \\
\end{array}$ \\
\hline Software & Lawson M3 SCP & Lawson M3 SCP & i2 SCP, DP, DF \\
\hline $\begin{array}{l}\text { Model } \\
\text { design }\end{array}$ & $\begin{array}{l}\text { Cost optimisation. Infinite } \\
\text { capacity. }\end{array}$ & $\begin{array}{l}\begin{array}{l}\text { Cost optimisation. } \\
\text { capacity. }\end{array} \\
\text { cinite } \\
\end{array}$ & $\begin{array}{l}\text { Profit optimisation. Finite } \\
\text { capacity. }\end{array}$ \\
\hline $\begin{array}{l}\text { Planning } \\
\text { data }\end{array}$ & Manually from ERP & $\begin{array}{l}\text { Imported from ERP and Excel } \\
\text { spreadsheets. }\end{array}$ & $\begin{array}{l}\text { Imported from ERP, through own } \\
\text { data base }\end{array}$ \\
\hline $\begin{array}{l}\text { Planning } \\
\text { organisation }\end{array}$ & $\begin{array}{l}1 \text { person gathers data, } 1 \text { material } \\
\text { planner, } 1 \text { distribution planner, } 2 \\
\text { consultants and } 1 \text { SCP. }\end{array}$ & $\begin{array}{l}\text { One central master planner and } \\
\text { local requirements planners at } \\
\text { each site that works in } \\
\text { accordance to the central plan. }\end{array}$ & $\begin{array}{l}\text { Salesmen register individual } \\
\text { forecasts and makes delivery } \\
\text { promises. } 3 \text { master planners } \\
\text { responsible for the process. }\end{array}$ \\
\hline $\begin{array}{l}\text { Planning } \\
\text { effects }\end{array}$ & $\begin{array}{l}\text { Found the scenario of lowest } \\
\text { cost. The total cost of the } \\
\text { optimum scenario lower than the } \\
\text { base line scenario. Not everyone } \\
\text { was committed to the result. }\end{array}$ & $\begin{array}{l}\text { Reduced total costs and inventory } \\
\text { levels. Increased communication } \\
\text { and control. Lower fill rates and } \\
\text { higher transportation costs. }\end{array}$ & $\begin{array}{l}\text { Increased delivery performance } \\
\text { and communication in the supply } \\
\text { chain. Balanced capacity } \\
\text { utilisation and decreased } \\
\text { inventory levels. }\end{array}$ \\
\hline
\end{tabular}

\subsection{Planning complexity}

The planning situations in all three cases can be characterised as being complex. The type of complexity differs, however, between the companies. For AAK, the planning complexity was caused by a large number of variables related to the physical supply chain structure (e.g. multiple production sites, production processes, products, markets) to include in a total cost calculation. For SL and SSAB the complexity was caused by both a large number of physical supply chain structure variables but also to multiple business constraints and decision rules, affecting the feasibility of the master plan. This was especially true for SSAB. The high levels of complexity were the main reason for all companies to implement APS in the first time. The complexity levels of all cases were considered too high to solve without APS. 
Full reference: Jonsson, P., Kjellsdotter, L., Rudberg, M. 2007. Applying advanced planning systems for supply chain planning: three case studies. International Journal of Physical Distribution and Logistics Management. 37(10): 816-834.

\subsection{Planning model and design}

When the planning problem complexities increase, the complexity of the optimisation conducted in the planning model also increases. The optimisation complexities differed between the cases. AAK conducted cost optimisation using infinite capacity while SL and SSAB used cost and profit optimisation with fixed product price, respectively, using finite capacity. Finite planning puts higher requirements on up-dated work centre data, compared to infinite planning. This should be especially critical on more detailed planning levels when working with short time buckets, which was not the case in the studied cases. Profit optimisation requires sales data in monetary figures. SSAB had the highest optimisation complexity of the three studied cases, not only because of its use of profit optimisation and finite capacity in several capacity units but also because of the high decision making complexity they wanted to consider in the planning model. This may have affected the acceptance of and commitment to the plans. Most identified references describing successful APS implementations (e.g. Brown et al., 2001, Gupta et al., 2002) are based on non-standardised software. The possibility of solving the actual planning problems depends on the type of APS system used. In standardised APS it may be impossible to model the actual complexity and solve the resulting optimisation model in a realistic way. The necessary assumptions and simplification of the problem, for example regarding capacities and economies of scale, may in some situations have great impact on the usefulness of the output. At AAK and SSAB, several simplifications were necessary in order to use standardised APS. Still, the perception was that the output was good enough.

\subsection{Planning data}

The gathering and registering of basic data was not considered to be problematic in any of the cases. Gathering and registering basic data in a cost efficient way and resulting in availability of high quality planning information should be more critical when working with close to real time data in finite planning models with short planning buckets and high planning frequency (APICS, 2007). The capable-to-promise calculation in the SSAB case was the only planning process working in real time with customer orders. All the other planning processes worked with longer time horizons, driven mainly by forecast data. In the AAK case, where the optimization was carried out only at one time, all data registration was however conducted manually. If running the model a second time, several of the manual activities could be eliminated. Consequently, the data gathering and registration processes were not critical in the present planning environments, characterised of vertically integrated supply chains consisting of one or multiple sites and the basic data possible to up-load from a common ERP system.

\subsection{Planning organization}

For all three cases, several organizational units were involved and affected by the planning process. Thus, an important aim was also to create commitment to an "optimum and feasible" plan through out the organization. For AAK the cost optimized output was considered the most important output of the planning but for SL and SSAB, using APS in the master planning processes, it was almost more important to generate commitment to one single plan through out the organization rather than finding the optimum plan. Still, the cost and profit optimizations were considered important for SL and SSAB and commitment very important 
Full reference: Jonsson, P., Kjellsdotter, L., Rudberg, M. 2007. Applying advanced planning systems for supply chain planning: three case studies. International Journal of Physical Distribution and Logistics Management. 37(10): 816-834.

for AAK. In all cases, one business unit was formally responsible for setting-up and running the APS-based planning. In the AAK case, other business units that were affected by the planning output were not involved during any phase of the planning. This resulted in existence of parallel plans and very low commitment to all generated plans. In SL and SSAB, the responsible business units acted as centralized planning functions. They worked actively with the involved parts (sales, production, etc.), with planning meetings but also with education and training. This was especially the case at SSAB. Still, no true collaborative planning, as outlined in for example the CPFR or Sales and Operations Planning concepts (Stadtler and Kilger, 2005) was conducted. The planning was the "show" of only a few people. The lack of involvement of the other functions and processes may have had negative impact of the planning performances and commitment to the generated plans. This was however not studied here.

\subsection{Planning effects}

The perceived effects of APS cannot be analysed in isolation from the context where it is used, for example, the design and function of the planning organisation. An appropriate planning organization is most likely necessary for utilizing the potential of the APS, and the commitment to the plan generated by the APS. APS usage could also improve the acceptance and trust in a centralized planning organization as such, resulting in common priorities and commitment to single plans. The relationships between planning organization, APS usage and performance effects were not analysed in detail in this study. However, some observations were made. In the AAK case, optimization results indicate that the performance effects could be significant but the lack of involvement in the process and commitment to the results reduce the real performance effects. In the SL case, the APS implementation was conducted together with a structural change in the planning processes and centralization of the planning organisation. All changes should impact the commitment to a centrally generated plan and the operative planning performance in positive ways. In the SSAB case, the APS usage was also supported by a centralized planning function, however, belonging to the marketing function, which was one of the functions to be coordinated in the centralised planning process. In none of the cases a centralized planning organization was set up in order to monitor critical path of the supply chain, conduct what-if analysis, event-based re-planning, etc. The ambitions were to manage the steady-state master production scheduling processes.

\section{Concluding remarks and further research}

Advanced planning systems (APS) are identified as potential support tools for managing complex supply chain planning problems and as means for supply chain integration. This article fills some of the knowledge gaps about how this could be done and the perceived effects of using APS, focusing on the strategic and tactical planning levels. Three explorative case studies show how APS can enhance supply chain management in various situations. Noteworthy is that all three cases are centred on the software use of a so-called supply chain planning (SCP) module, but the module is used on different planning levels addressing different problems. One of the cases uses the SCP as a strategic network design tool. The two reminding cases use it as a tactical master planning tool, one in a single site setting and one in a multi-site setting including both production and distribution issues. Hence, the SCP module as such must be considered fairly general indicating a wide area of application for tactical APS modules. Similar 
Full reference: Jonsson, P., Kjellsdotter, L., Rudberg, M. 2007. Applying advanced planning systems for supply chain planning: three case studies. International Journal of Physical Distribution and Logistics Management. 37(10): 816-834.

findings have been reported in literature. Brown et al. (2001), for example, show how Kellogg's uses the same module for both strategic network design and for multi-site master planning. This further highlights that companies must treat APS with caution and put a lot of effort into the four issues of planning complexity, model design, suitable planning data and a proper planning organisation. In our cases, supply chain planning software, based on linear and mixed integer programming, could support a cost optimised strategic network design in a merger of two companies, production and volume allocation in one case, and how efficiency, capacity utilisation and delivery service problems were considered and decreased in two cases. These latter two cases also showed how APS can support the integration between the marketing and production functions and the commitment to a common plan throughout the supply chain. The relationships between APS, planning organisation and planning effects are thus obvious in these cases.

Several positive effects of using APS as support for global supply chain planning on strategic and tactical levels were identified, but the research conducted here also identifies and motivates several future research areas about the appropriateness and performance of APS usage. Based on the areas described in the last section of the frame of references and explored in the case analysis, several different research issues related to the following areas can be motivated: 1) the feasibility of APS in situations with various planning complexities, 2) how design of the optimisation model create complexity and affects the planning process, 3) data gathering requirements when using APS, 4) the role and design of the planning organisation, and 5) how to achieve positive planning effects, such as finding the global optimum of plans, global commitment to the same plan and developing supply chain process integration.

\section{References}

Andersson, J. (2005) Avancerade planeringssystem som beslutsstöd vid produktions- och distributionsplanering, Master's thesis, ITN, Linköping University, Sweden.

APICS (2007), Using information technology to enable supply chain management, APICS Certified Supply Chain Professional Learning System, APICS.

Arntzen, B.C., Brown, G.G., Harrison, T.P. and Trafton, L.L. (1995) "Global Supply Chain Management at Digital Equipment Corporation”, Interfaces, Vol. 25, No. 1, pp. 69-93.

Brown, G., Keegan, J., Vigus, B. and Wood, K. (2001) "The Kellogg Company Optimizes Production, Inventory and Distribution”, Interfaces, Vol. 31, No. 6, pp. 1-15.

Choi, T. and Krause, D. (2006), "The supply base and its complexity: implications for transaction costs, risks, responsiveness and innovation, Journal of Operations Management, Vol. 24, pp. 637-652.

Chopra, S. and Meindl, P. (2004) Supply Chain Management - Strategy, Planning and Operation, $2^{\text {nd }}$ edition, Prentice Hall, New Jersey.

Colotla I, Shi Y and Gregory M (2003) "Operation and performance of international manufacturing networks”, International Journal of Operation and Production Management, Vol. 10, pp. 1184-1206.

De Kok, A.G. and Graves, S.C. (2003) Handbook in operations research and management science Vol. 11 - Supply Chain Management: Design, Coordination and Operation, Elsevier, Amsterdam. 
Full reference: Jonsson, P., Kjellsdotter, L., Rudberg, M. 2007. Applying advanced planning systems for supply chain planning: three case studies. International Journal of Physical Distribution and Logistics Management. 37(10): 816-834.

Entrup, M.L. (2005) Advanced Planning in Fresh Food Industries, Physica-Verlag/Springer, Heidelberg.

Fleishmann, B. and Meyr, H. (2003) "Planning Hierarchy, Modeling and Advanced Planning Systems”, in De Kok, A.G. and Graves, S.C. (Ed.), Handbook in operations research and management science Vol. 11 - Supply Chain Management: Design, Coordination and Operation, Elsevier, Amsterdam, pp. 457-524.

Goetschlalckx, M., Vidal, C.J. and Dogan, K. (2002) "Modeling and design of global logistics systems: A review of integrated strategic and tactical models and design algorithms”, European Journal of Operational Research, Vol. 143, pp. 1-18.

Gupta, V., Peter, E., Miller, T. and Blyden, K. (2002) "Implementing a Distribution-Network Decision-Support System at Pfizer/Warner-Lambert”, Interfaces, Vol. 32, No. 4, pp. 28-45.

Kylén J-A (1994), Fråga rätt: vid enkäter, intervjuer, observationer och läsning, Stockholm.

Melo M.T, Nickel S. Amd Saldanha da Gama F (2005), "Dynamic multi-commodity capacitated facility location: a mathematical modeling framework for strategic supply chain planning”, Computer \& Operations Research, Vol. 33, pp 181-208.

Meyr, H., Wagner, M. and Rohde, J. (2005) “Structure of Advanced Planning Systems”, in Stadtler and Kilger (Ed.), Supply Chain Management and Advanced Planning, Springer, Berlin, pp. 109-115.

Muscatello, J., Small, M., Chen, I. (2003) "Implementing enterprise resource planning (ERP) systems in small and midsize manufacturing firms”, International Journal of Operations and Production Management, Vol. 23, No. 8, pp. 850-871.

Petroni, A. (2002) “Critical factors of MRP implementation in small and medium-sized firms", International Journal of Operations and Production Management, Vol. 22, No. 3, pp. 329348.

Stadtler, H. (2005) "Supply chain management and advanced planning - basics, overview and challenges”, European Journal of Operations Research, Vol. 163, pp. 575-588.

Stadtler, H. and Kilger, C.(2005) Supply Chain Management and Advanced Planning Concepts, Models, Software and Case Studies, $3^{\text {rd }}$ edition, Springer, Berlin.

Wortmann, J.C., Muntslag, D.R. and Timmermans, P.J.M. (1997) Customer-driven Manufacturing, Chapman \& Hall, London, UK.

Wu, J., Ulieru, M., Cobzaru, M. and Norrie, D. (2000) "Supply Chain Management Systems: state of the art and vision", International Conference on Management of Innovation and Technology (ICMIT).

Zoryk-Schalla A., Fransoo J and de Kok T.G (2004) "Modeling the planning process in advanced planning systems”, Information and Management, Vol. 42, pp. 75-87. 